\title{
Novas Mídias: Lugar de Opinião? Lugar de Informação?
}

\author{
Priscila Muniz de Medeiros \\ Universidade Federal de Pernambuco - prismuniz@gmail.com \\ Mestranda no Programa de Pós-Graduação em Comunicação \\ da Universidade Federal de Pernambuco. Bolsista da Capes. \\ TENAFLAE DA SilVA LôRDElo \\ Universidade Federal de Pernambuco - tenaflae@gmail.com \\ Mestre em Comunicação pela Universidade Federal da Bahia (UFBA), \\ doutorando em Comunicação pela Universidade Federal de Pernambuco (UFPE), \\ bolsista da FACEPE, Prof. Msc. do Curso de Comunicação Social \\ com habilitação em Jornalismo da Faculdade do vale do Ipojuca (Favip).
}

\section{Resumo}

A liberação da emissão promovida pelo ciberespaço associada à possibilidade de visibilidade pública dos conteúdos vem gerando discussões diversas sobre, por um lado, o potencial de um novo ambiente de deliberação pública e de um maior espaço para a comunicação nãohegemônica e, por outro, a legitimidade e credibilidade da imensa gama de informações em circulação. O objetivo desse trabalho é discutir a circulação de opinião e informação no ciberespaço e suas consequentes implicações sociais. Para tanto, serão utilizados elementos da pesquisa intitulada "O papel das novas mídias no debate ambiental: uma análise dos fluxos comunicativos online sobre as mudanças no código florestal brasileiro".

\section{Palavras-chave}

Mídias sociais, espaço público, democracia.

\begin{abstract}
The subversion of the place of emission promoted by the cyberspace in connection with the possibility of public visibility of the contents is bringing on several discussions about, on the one hand, the possibility of a new environment of public deliberation and of a wider space for a non-hegemonic communication and, on the other hand, the legitimacy and credibility of the wide range of information in circulation. This paper aims to discuss the circulation of opinion and information in the cyberspace as well as its social implications. For such purpose, it will be used some data from the research "The place of new media in the environmental discussions: an analysis of online communicative flows regarding the changes in Brazilian forestall code".
\end{abstract}

Keywords

Social media, public space, democracy.

Artigo recebido em 13/03/2012

Aprovado em 29/03/2012 
Estudos em Jornalismo e Mídia - Vol. $9 \mathrm{~N}^{\circ} \mathrm{I}$ - Janeiro a Junho de 2012 ISSNe 1984-6924

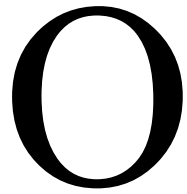

presente artigo é parte integrante da pesquisa intitulada "O papel das novas mídias no debate ambiental: uma análise dos fluxos comunicativos online sobre as mudanças no código florestal brasileiro". Trata-se de uma discussão teórica acerca de alguns dos pontos que tangenciam a pesquisa. Além disso, algumas hipóteses e tendências serão apontadas.

\section{Comunicação e poder}

Ao longo da história, a censura só existiu porque interesses específicos se sentiram ameaçados por fluxos de comunicação cujos conteúdos poderiam, de alguma forma, prejudicá-los. Seja a igreja católica proibindo a circulação de certos livros, sejam os governos ditatoriais controlando os veículos de comunicação: em todos os casos de censura, o silenciamento tem uma forte conexão com a manutenção do poder. Nesse sentido, a recíproca também é verdadeira: qualquer movimento que vise a mudanças efetivas nas sociedades não pode precindir da comunicação. "Poder é mais do que comunicação, e comunicação é mais do que poder. Mas o poder se fia no controle da comunicação, assim como o contra-poder depende da ruptura de tal controle" (CASTELLS, 2009, p. 3).

Nas sociedades democráticas marcadas pela cultura de massa, o fácil acesso a conteúdos midiáticos não modificou a lógica do controle do poder pelo silenciamento de diferentes visões de mundo. Se as ditaduras censuravam promovendo, através da proibição, a ignorância, o capital silencia se apoderando dos meios de produção de mensagens midiáticas, bombardeando os receptores com conteúdos arraigados na lógica do entretenimento e esvaziando, assim, o interesse por discursos políticos. É por isso que o surgimento de novos meios de comunicação sempre provocou uma corrida por seu controle. "Os receptores são, pela própria natureza da comunicação de massa, parceiros desiguais no processo de intercâmbio simbólico" (THOMPSON, 1995).

Como destaca Venício Lima (2010), nas sociedades democráticas atuais, o poder do Estado não é o principal agente da censura: 
Enquanto isso, entre nós, "o mercado" continua absoluto como única forma admitida pela indústria das comunicações como critério e medida das liberdades de expressão e de imprensa. Qualquer alusão à necessidade de algum tipo de regulação democrática do setor, feita por quem quer que seja, será liminarmente estigmatizada como autoritarismo, stalinismo, totalitarismo. Quase 20 anos depois do fim da ditadura, em plena democracia, continuamos a ignorar, no Brasil, a evidência de que, junto com outras atividades anteriormente consideradas como exclusivas do Estado, a censura também está sendo privatizada (LIMA, 2010, p.105).

\section{O papel da opinião púbica}

O controle da comunicação está intrinsecamente associado ao poder de influência sobre a opinião pública, levando-se em conta a capacidade de promover mudanças políticas de que tal opinião é munida. Para Habermas, é através dos fluxos comunicacionais que emanam do espaço público em direção aos centros do poder que pode ocorrer a influência política por parte dos cidadãos. Ou seja, a opinião pública, surgida através dos espaços de deliberação no interior do espaço público, tem o papel de direcionar o poder administrativo (HABERMAS, 1997).

Por espaço público, Habermas entende a instância que, para ele, se configura enquanto a arena na qual se forma a opinião pública. O autor toma como base o que ele chama de esfera pública burguesa, que teria surgido como fonte de resistência à autoridade estatal da monarquia absolutista. Sua origem estaria ligada à esfera pública literária, formada através de discussões públicas nos espaços dos cafés europeus. Nesses locais, as pessoas letradas passaram a se reunir, de forma privada, para fazer a leitura de jornais políticos e discutir as questões de interesse público. Ainda na mesma obra, Habermas afirma que a massificação dos meios de comunicação ocasionou uma mudança estrutural na esfera pública. Se, por um lado, tais meios de comunicação ganharam um alcance inédito, ampliando, com isso, a esfera pública, eles também passaram a ser mais vulneráveis a interesses particulares, esvaziando o sentido público da mesma (HABERMAS, 1884).

Quando Habermas decretou a mudança estrutural da esfera pública, ele se referia basicamente à apropriação comercial dos meios de comunicação. Para o autor, a partir 
do momento em que os interesses privados passam a ditar os rumos dos veículos de comunicação, esses passam a criar uma falsa consciência de que os consumidores são responsáveis pela criação de uma opinião pública, quando, na verdade, o que existe é uma "opinião pública encenada", criada a partir de processos de manipulação (HABERMAS, 1984).

Thompson (1995) levanta objeções à visão de Habermas ao afirmar que ela “exagera a passividade dos indivíduos e o quanto eles são orientados para, e influenciados pelo, consumo das mensagens da mídia" (THOMPSON, 1995, p. 152).

E mais: ao assumir como dada a eficácia política das mensagens da mídia, sua argumentação tende a negligenciar o novo tipo de fragilidade que os processos políticos adquirem na era da comunicação de massa. (...) é devido ao fato de os processos políticos acontecerem, hoje, num ambiente social que é "rico em informação" - isto é, onde os indivíduos têm mais acesso do que nunca à comunicação e informação transmitida via meios técnicos - que os líderes políticos e os funcionários do estado procuram, sempre mais, controlar, e tornam-se, cada vez mais, vulneráveis devido a sua inabilidade de controlar, totalmente, a difusão das imagens e as informações das quais o exercício do seu poder, em parte, depende (THOMPSON, 1995, p. 152).

Pensando no contexto das sociedades contemporâneas, marcadas pela cultura de massa, tais objeções só parecem ser plenamente adequadas quando existem veículos independentes fortes, capazes de enfrentar as manipulações das mídias aliadas a interesses específicos. De pouco adianta ter disponível uma grande gama de informações se os veículos que as emitem estão ideologicamente alinhados aos mesmos interesses políticos e econômicos. Pensando na questão ambiental, por exemplo, é difícil imaginar qualquer veículo de comunicação que mobilize amplamente seu jornalismo em torno de um tema como, por exemplo, o consumo consciente, se isso significar contrariar os interesses de seus anunciantes. Temos que levar em conta que, nas mídias de massa, os gatekeepers têm o poder de decidir o que ganhará ou não visibilidade pública. Van Dijk (2008) chama a atenção, entre outras coisas, para o risco das representações generalizadas do mundo: 
Se os receptores leeem ou escutam muitos discursos semelhantes de políticos ou da mídia e não têm informações alternativas concorrentes, tais modelos podem, por sua vez, ser generalizados para representações abstratas e socialmente partilhadas sobre, por exemplo, os muçulmanos, as minorias, o povo inglês e a imigração, os preconceitos étnicos e as ideologias nacionalistas ou racistas (VAN DIJK, 2008, p 207).

São essas representações acumuladas que as pessoas tendem a acionar no momento em que recebem novas mensagens midiáticas. Tal articulação ideológica faz com que, mesmo não sendo passivos diante das mensagens da mídia, os indivíduos as percebam através de lentes distorcidas. Mais adiante, veremos que o apontamento de Thompson parece mais adequado se o pensarmos a partir da emergência dos novos meios que ampliam os pólos de emissão das mensagens (LEMOS, 2009).

Podemos concluir, então, que a ideia de uma opinião pública legítima fica comprometida num sistema onde a visibilidade dos discursos políticos dependa quase que integralmente dos veículos de comunicação de massa, marcados pela influência de uns poucos emissores de mensagens e frequentemente aliados a interesses políticos e econômicos específicos. Isso não quer dizer que não haja espaço para discursos contrahegemônicos na chamada "grande mídia". Mesmo esses veículos, para manterem sua legitimidade social, devem deixar abertos poros para a penetração das aspirações da sociedade civil (ESTEVES, 2003). Ainda assim, a mediação dos veículos faz com que os espaços para discursos contra-hegemônicos não distorcidos quase sempre sejam pequenos e esporádicos, e, por isso, os mesmos tendem a se perder com freqüencia dentro do ambiente de entretenimento característico das mídias de massa.

\section{Esfera de visibilidade pública e esfera de discussão pública}

Ao refletir sobre a esfera pública habermasiana, Wilson Gomes (2008) divide a mesma, que ele também chama de publicidade social, em dois conceitos distintos: a esfera da visibilidade pública, de caráter expositivo, e a esfera da discussão pública, argumentativa. A ideia central é que a esfera pública não é somente constituída pelo debate público, mas também por uma cena pública capaz de apresentar à sociedade civil temas que mereçam atenção, fornecendo elementos para o debate. Para o bom 
funcionamento da esfera de visibilidade pública, Gomes considera fundamental o poder de alcance dos veículos de comunicação.

Enfim, a esfera de visibilidade pública é, além disso, fundamental para a esfera de discussão pública numa democracia de massa por pelo menos duas razões: a) a esfera pública deliberativa precisa da exposição da esfera de visibilidade pública para cumprir o seu papel de discussão aberta a todos os concernidos. (...) b) a esfera de visibilidade pública torna disponíveis, ainda que na maior parte das vezes não o produza, os temas de interesse público que são introduzidos no debate público ou que provocam a instalação de debates públicos, internos ou externos à própria cena pública (GOMES, 2008, p. 136).

Para Gomes, ambas as esferas são interdependentes na construção de uma democracia sólida, e quase sempre caminham juntas. A ideia de esfera de visibilidade pública está associada a fluxos de informação, que vão servir como matéria prima para a formação das opiniões que serão expostas na esfera do debate público. Confrontadas através de argumentos, tais opiniões darão origem à opinião púbica. É neste sentido que analisaremos, a seguir, o papel dos novos meios enquanto espaços de circulação de opiniões e informações, levando em conta o que se acredita serem as vantagens e os problemas inerentes a tais ambientes comunicacionais.

\section{Mais opiniões em circulação}

No encalce das novas tecnologias da informação e comunicação, surgiram debates sobre a possibilidade de uma reanimação da esfera pública a partir de deliberações e mobilizações articuladas online. Foram algumas características inerentes ao ciberespaço que fizeram com que ele começasse a ser encarado como um ambiente comunicacional potencialmente mais democrático do que as mídias de massa. Sites independentes e blogs, por exemplo, permitem que qualquer indivíduo ou organização com um mínimo de conhecimento digital possa expor publicamente suas ideias, ao passo que as mídias sociais, além de funcionarem como espaços de conversação, conseguem dar visibilidade a fluxos comunicacionais advindos de pessoas ou grupos sem recursos financeiros significativos.

André Lemos (2009) é um dos autores que defendem que o surgimento de mídias de função pós-massiva pode fazer com que sejam resgatados elementos do 
debate público e da ação política. Diferente das funções massivas, nas quais os conteúdos são transmitidos num modelo unidirecional, as pós-massivas trabalham numa perspectiva de comunicação multidirecional, onde ocorrem fluxos comunicativos de todos para todos.

Emerge aqui uma nova esfera conversacional em primeiro grau, diferente do sistema conversacional de segundo grau característico dos mass media. Neste, a conversação se dá após o consumo em um rarefeito espaço público. Naquele, a conversação se dá no seio mesmo da produção e das trocas informativas, entre atores individuais ou coletivos. Esta é a nova esfera comunicacional pós-massiva. (...) Assim, as funções pós-massivas, por serem mais conversacionais que informacionais, podem resgatar algo da ação política, do debate, do convencimento e da persuasão, outrora desestimulados pela cultura de massa (LEMOS, 2009, p. 10-12).

Nesse contexto, a colocação de Thompson (1995) parece se aplicar melhor, já que o ciberespaço permite a emissão e a visibilidade de pontos e vista múltiplos, ligados a interesses distintos e que podem fugir do controle de monopólios ideológicos. Segundo Castells (1999)

É precisamente devido a sua diversificação, multimodalidade e versatilidade que o novo sistema de comunicação é capaz de abarcar e integrar todas as formas de expressão, bem como a diversidade de interesses, valores e imaginações, inclusive a expressão de conflitos sociais (CASTELLS, 1999, p.461).

Apesar das novas potencialidades trazidas pelas NTICs, é preciso ter em vista que, frequentemente, a comunicação no ciberespaço continua obedecendo a preceitos instaurados pela comunicação de massa, como, por exemplo, a lógica do entretenimento, presente em boa parte das trocas conversacionais nas mídias sociais. Cabe então investigar até que ponto tais potencialidades estão de fato se concretizando e até que ponto elas continuam sendo apenas promessas. O que temos de concreto é que, diferente dos veículos de comunicação de massa, as novas mídias proporcionam, para os cidadãos comuns, espaços de manifestação política que não pressupõem a mediação de um jornalista. E tais articulações de opiniões políticas podem, inclusive, culminar no surgimento de movimentos políticos articulados através de mídias sociais, como é o 
Estudos em Jornalismo e Mídia - Vol. $9 \mathrm{~N}^{\circ} \mathrm{I}$ - Janeiro a Junho de 2012 ISSNe 1984-6924

caso dos vários movimentos de jovens acampados que se espalharam pelo mundo no ano de 2011. Com reivindicações variadas, que incluíam quase sempre mudanças no sistema político de modo a garantir uma maior participação popular nas decisões, as manifestações públicas, divulgadas através da internet, fizeram com que milhões de pessoas fossem às ruas.

A intervenção dos usuários nos fluxos de comunicação do ciberespaço ocorre também através da vigilância sobre os conteúdos da mídia tradicional. Com os novos espaços de exposição, eles passam a questionar versões e posturas que julgam inadequadas por parte dos veículos tradicionais. Na análise ainda parcial do corpus da pesquisa, essa tendência se confirmou em pelo menos um momento: quando um usuário do Twitter postou o seguinte comentário: “Outra coisa, a cobertura da votação do código florestal, na Band, foi orientada pela bancada ruralista do congresso. \#quemviuviu".

Se parece ser pouco questionado o potencial de o ciberespaço fazer com que mais opiniões circulem, incluindo os discursos de grupos que antes não tinham acesso à voz nos meios tradicionais, a circulação de informações nas novas mídias é encarada por muitos com desconfiança.

\section{Da colaboração aos boatos na rede}

Conforme demonstrado anteriormente, a esfera da visibilidade pública tem um papel fundamental na construção de uma opinião pública legítima, já que ela fornece os elementos para o debate público. E para discutir informação e democracia, é indispensável que se inclua o debate sobre a proferida imparcialidade jornalística. Como inúmeros autores já colocaram, tal imparcialidade é impraticável, uma vez que o indivíduo ou organização em questão aciona sua visão de mundo desde o momento em que escolhe o tema a ser tratado até o momento de decidir que espaço o assunto ocupará no noticiário ou na editoria em questão, passando necessariamente pelo direcionamento que dará à notícia.

Se a concretização de uma real imparcialidade é inviável, ela não deve ser o objetivo do jornalismo. Mais do que imparcial, o jornalismo deve ser um serviço público que tenha como principal meta atender ao interesse da coletividade. No entanto, 
em vários momentos é possível perceber que os veículos de comunicação de massa, inseridos numa lógica comercial, se propõem antes a atender a interesses específicos do que ao bem público. Levando isso em conta, alguns autores também defendem que os novos meios podem funcionar como uma contramola também no que diz respeito à circulação de informações.

No cenário digital, da forma como a internet foi estruturada, o capital controla a infra-estrutura de conexão, mas não controla os fluxos de informação, nem consegue determinar as audiências. Também não pode impedir o surgimento de portais e sites independentes e desvinculados do poder político e econômico. Com o surgimento da blogosfera e de outras ferramentas colaborativas, o capital passa a ter que disputar as atenções como nunca ocorrera no capitalismo industrial (SILVEIRA, 2008, p. 34).

Nessa perspectiva, os usuários deixam de ser apenas consumidores de informações, passando a adquirir também um papel de produção e mediação. Fenômenos como a Wikipédia, os sites de jornalismo colaborativo, a blogosfera e a circulação de informações nas mídias sociais são exemplos dessa nova relação. Isso se enquadra no que Axel Bruns (2008) chamou de Produsage.

O que emerge é que, na economia da informação online e em rede, os participantes não são apenas consumidores passivos, mas usuários ativos, sendo que alguns deles participam principalmente com foco apenas em seu uso pessoal, enquanto outros participam mais fortemente de formas que são inerentemente construtivas e produtivas de redes sociais e conteúdos comunais (BRUNS, 2008, p. 23, tradução minha).

A ideia de produsage está fortemente associada à colaboração no ciberespaço. Uma das grandes armas para esse processo de colaboração é a disponibilidade de acesso à imensa gama de conteúdos armazenados nos bancos de dados online. As informações no ciberespaço podem ser transformadas por outros usuários. Isso configura uma das características que Manovich (2001) atribuiu à internet: a variabilidade, possível graças às codificações numéricas do meio digital. Ele diz que, enquanto a antiga mídia envolvia seqüência de elementos que eram estocadas em algum material, estabelecendo uma ordem determinada uma vez e para sempre, a nova mídia, em oposição, é 
Estudos em Jornalismo e Mídia - Vol. $9 \mathrm{~N}^{\circ} \mathrm{I}$ - Janeiro a Junho de 2012 ISSNe 1984-6924

caracterizada pela variabilidade. Os processos de produção colaborativa de informações surgem como meios de dar visibilidade a temas e fatos que, ou são esquecidos pelos veículos de massa, ou são apropriados por eles de forma previamente moldada, que deixa de lado abordagens condizentes com múltiplas visões de mundo. Um dos objetivos do projeto "O papel das novas mídias no debate ambiental: uma análise dos fluxos comunicativos online sobre as mudanças no código florestal brasileiro" é justamente procurar identificar discursos voltados para um novo paradigma de civilização: um paradigma ecológico, baseado numa relação homem/natureza distinta da atual relação de força, dominação e exploração (MORIN, 2011; MOSCOVICI, 2007; SANTOS, 1999). A hipótese a ser testada é a de que tais discursos contra-hegemônicos estariam encontrando, em manifestações que emanam das novas mídias, um espaço maior de propagação do que o pouco ou nenhum que apresentam nas mídias tradicionais. Neste sentido, não só as opiniões sobre o tema são relevantes, mas a própria produção de fluxos informativos alternativos. Prado e Becker (2011) apontam que

Contra a postura liberal hegemônica, inúmeras redes sociais têm se constituído como uma via de mudança nos termos da contagem das parcelas do social. Sugerimos que os processos colaborativos de construção da notícia na web podem se constituir como formas nãohegemônicas e independentes de produção, gestão e circulação da informação que devem ser investigados. Embora não garantam um jornalismo de maior qualidade, promovem uma reconfiguração da prática jornalística e de sua mediação social (PRADO, BECKER, 2011, p. 42).

Para além dos benefícios provocados pela falta de controle sobre o pólo emissor, ela também faz com que as novas mídias sejam utilizadas para a propagação de boatos e informações falsas. É por isso que muitos questionam a qualidade e a credibilidade das informações que circulam nas mídias sociais. Após ressaltar o processo histórico de construção da credibilidade pelo jornalismo, Muniz Sodré e Raquel Paiva (2011) questionam a validade das informações publicadas nas redes em virtude da falta de mediação. 
Fala-se de "mídias complementares" sem perceber que as regras de produção de veracidade valem apenas para um campo técnico (o do jornalismo) com limites traçados, ao longo dos tempos, por sutis negociações discursivas, entre os sistemas profissionais e seus públicos. Sem esse jogo semiótico, entram em cena a mentira e o boato (SODRÉ, PAIVA, 2011, p.31).

A discussão dessa questão exige que algumas considerações sejam feitas. A primeira delas diz respeito ao fato de que qualquer forma de comunicação pressupõe ideologias, se adotarmos o sentido neutro do termo (aquele que não diz respeito apenas a relações de dominação). E as informações que circulam no ciberespaço não fogem à regra. Então, seja em virtude de uma ação intencional ou de um erro no processo de apuração, a circulação de informações falsas nas mídias sociais pode ocorrer, como de fato ocorre. A diferença é que, muito mais do que nos veículos de massa, os novos meios contam com espaços para o contraditório, para a contestação de informações tidas como falsas. E através de tais embates os boatos e mentiras tendem a ser desmascarados. "No caso do boato virtual e da circulação de informações falsas, ao mesmo tempo em que a rede ajuda o boato a atingir proporções cada vez maiores, ela também facilita para que o boato seja desmentido" (ZAGO, 2011, p. 34).

Sodré e Paiva defendem que o desmentido não ganha o mesmo alcance do boato, já que "o boato predomina pela força sedutora do imaginário, é mais 'virótico' do que a comunicação do fato" (SODRÉ, PAIVA, 2011, p.31). Respeitando a particularidade de cada caso específico, tendemos a crer que os interesses existentes na denúncia do boato encontram no ciberespaço campo suficiente para a circulação do desmentido. Espaço seguramente maior do que o que é tradicionalmente concedido pelo jornalismo, que costuma reservar para erratas e desmentidos apenas um pequeno espaço escondido entre as páginas dos jornais. Mesmo o jornalismo tradicional, com toda a construção histórica da credibilidade, nunca foi imune à difusão de informações falsas, fantasiadas, distorcidas ou à omissão de informações relevantes.

Outro ponto que deve ser levado em consideração é que a circulação de boatos no ciberespaço não é regra. Nem tudo que é postado na rede vai ganhar credibilidade instantânea a ponto de ser endossado e repassado pelos usuários, já que os mesmos 
podem adotar critérios próprios para julgar se uma informação merece ou não confiança. É fácil perceber, por exemplo, que na rede social Twitter, a maior parte das informações que circulam sobre um determinado tema são oriundas do jornalismo tradicional, que goza de um status de verdade maior do que indivíduos em particular. Isso não impede que tais informações sejam questionadas ou que surjam outros atores, alheios aos meios de comunicação de massa, que também passem a ser percebidos como merecedores de credibilidade. No caso da presente pesquisa, pelo menos até a atual fase da apuração dos dados, o perfil @florestafaz, projeto que reúne diversas ONGs ambientais num movimento contras a mudanças o código florestal, aparece como o mais "retuitado". Uma vez que uma parte significante do conteúdo gerado pelo perfil é informativo, podemos entender que ele adquiriu um status de confiabilidade entre os usuários que discutiram o tema código florestal nesta rede social.

Por fim, é importante desconstruir o mito dos 140 caracteres, que tende a desqualificar as informações que circulam nas redes sociais alegando que as mesmas são superficiais, graças aos limites de espaço impostos. Sodré e Paiva (2011), por exemplo, alegam que "perdem muito mais as novas gerações, que sequer podem imaginar-se lendo algo para além dos 143 toques do Twitter" (SODRÉ, PAIVA, 2011, p.29).

É verdade que o Twitter, por exemplo, não admite a postagem de conteúdos com mais de 140 caracteres, no entanto, no que diz respeito à circulação de informação nessa rede social, o espaço dos toques tende frequentemente a funcionar como uma chamada para um conteúdo maior, postado em sites ou blogs, que são conectados aos posts do Twitter através de ligações hipertextuais. A lógica é mais ou menos a mesma das manchetes dos jornais, que buscam chamar a atenção dos leitores para os conteúdos dos quais estão tratando. Também levando em conta os resultados parciais da análise, cerca de $70 \%$ dos tweets verificados sobre o tema código florestal apresentam links para outros conteúdos, sejam textuais ou audiovisuais. 


\section{Considerações finais}

Seja no que diz respeito à circulação de opiniões ou de informações, as novas mídias aparecem como espaços potenciais de democratização da comunicação, uma vez que, com a liberação da emissão, permitem o acesso de novos agentes tanto à esfera da visibilidade pública quanto à esfera do debate público, que estão intrinsecamente conectadas. Essa maior pluralidade faz com que mais visões de mundo circulem nas sociedades, diminuindo a concentração do poder de influência que os meios de comunicação de massa historicamente tiveram sobre a opinião pública.

Além disso, a participação dos cidadãos na produção e mediação de notícias e opiniões políticas pode vir a culminar no crescimento do interesse dos mesmos pelas questões públicas, o que pode contribuir com o surgimento de modelos democráticos mais fortes, baseados numa maior porosidade do sistema político a contribuições advindas da base ao topo.

É fato que o ciberespaço não garante a qualidade da informação, bem como não impede a propagação de boatos e mentiras. No entanto, o próprio caráter de pluralidade e colaboração do meio pode atuar na denúncia das informações falsas, controversas e de interesses privados camufladas em interesse público. Interesses particulares e ideologias também existem no ciberespaço, mas nele eles têm que conviver com outros interesses e outras ideologias, o que torna as disputas ideológicas menos desiguais.

\section{Referências}

BRUNS, Axel. Blogs, Wikipedia, Second Life and beyond: from production to produsage. Nova York: Peter Lang Publishing, 2008.

CASTELLS, Manuel. A sociedade em rede. São Paulo, Paz e Terra, 1999.

CASTELLS, Manuel. Communication Power. Nova York: Oxford University Press, 2009.

ESTEVES, João Pissarra. Espaço público e democracia: comunicação, processo de sentido e identidade social. São Leopoldo: Unisinos, 2003.

GOMES, Wilson. Da discussão à visibilidade. In: GOMES, Wilson; MAIA, Rousiley. Comunicação e democracia: problemas \& perspectivas. São Paulo: Paulos, 2008.

HABERMAS, Jürgen. Mudança estrutural da esfera pública: Investigações quanto a uma categoria da sociedade burguesa. Rio de Janeiro: Tempo Brasileiro, 1984. 
Estudos em Jornalismo e Mídia - Vol. $9 \mathrm{~N}^{\circ} \mathrm{I}$ - Janeiro a Junho de 2012 ISSNe 1984-6924

HABERMAS, Jürgen. Direito e Democracia: entre facticidade e validade. Rio de Janeiro: Tempo Brasileiro, volume II, 1997.

LEMOS, André. Nova esfera conversacional. In DIMAS, A. et al. Esfera pública, redes e jornalismo. Rio de Janeiro: Ed. E-Papers, 2009. p.9-30.

LIMA, Venício. Liberdade de expressão $\mathbf{X}$ liberdade de imprensa: direito à comunicação e democracia. São Paulo: Publisher Brasil, 2010.

MANOVICH, Lev. The language of new media. 2001. Disponível em $<$ http://andreknoerig.de/portfolio/03/bin/resources/manovich-langofnewmedia.pdf $>$. Acesso em 08 de maio de 2011.

MORIN, Edgar. Rumo ao abismo? Ensaio sobre o destino da humanidade. Rio de Janeiro: Bertrand Brasil, 2011.

MOSCOVICI, Serge. Natureza: para pensar a ecologia. Rio de Janeiro: Mauad X: Instituto Gaia, 2007.

PRADO, José Luiz Aidar; BECKER, Beatriz. Das modalizações para consumidores à reterritorialização de cidadãos politizados. In: Silva, Gislene. et al (org). Jornalismo contemporâneo: figurações, impasses e perspectivas. Salvador/Brasília: Edufba/Compós, 2011.

SANTOS, Boaventura de Souza. Pelas mãos de Alice: O social e o político na pós-modernidade. Porto: Afrontamento, 1999.

SCHIECK, Mônica. Ciberativismo: um olhar sobre as petições online. In: BOCC. Biblioteca On-line de Ciências da Comunicação, 2009. Disponível em: <http://www.bocc.ubi.pt/pag/schieck-monicaciberativismo.pdf $>$ Acesso em: 10 de maio de 2011.

SODRÉ, Muniz; PAIVA, Raquel. Informação e boato na rede. In: Silva, G. et al (org). Jornalismo contemporâneo: figurações, impasses e perspectivas. Salvador/Brasília: Edufba/Compós, 2011.

THOMPSON, John B. Ideologia e cultura moderna: teoria social crítica na era dos meios de comunicação de massa. Petrópolis: Vozes, 1995.

van DIJK, Teun A. Discurso e poder. São Paulo: Contexto, 2008.

ZAGO, Gabriela. Recirculação jornalística no Twitter: filtro e comentário de notícias por interagentes como uma forma de potencialização da circulação. 2011. Disponível em: < http://www.lume.ufrgs.br/handle/10183/28921> Acesso em 10 de junho de 2011. 
${ }^{i}$ Uma versão anterior desse artigo foi apresentada no V Simpósio Nacional da ABCiber, em Florianópolis em 2011. O texto foi aperfeiçoado e atualizado e foram acrescentados dados não disponíveis na época. 